\title{
How are Children Coping with the COVID-19 Pandemic? A Developing Country Perspective
}

\author{
Kadiann Hewitt-Thompson \\ Assistant Lecturer \\ The UWI School of Nursing \\ Mona, Kingston 7, Jamaica
}

\author{
Donnette Wright \\ PhD candidate \\ The UWI School of Nursing \\ Mona, Kingston 7, Jamaica
}

\begin{abstract}
This paper sought to discuss how children in developing countries are coping with the social, emotional and financial impact of the COVID-19 pandemic on their daily lives. Additionally, the evidence presented will increase awareness that children also experience varying impact of COVID-19 and provide guidance about coping mechanisms that may change the course of the impact and limit long term effects of the pandemic on them. It also explored the psychosocial influence of social determinants of children living in a developing country, the impact on their academic continuity and the role of parents in supporting children. Finally, the paper proposes pragmatic recommendations for achieving optimal social outcomes for children who experience pandemics.
\end{abstract}

Keywords:- Covid-19 pandemic, strategies for coping, children coping with pandemic, online education, access to the internet, play.

\section{INTRODUCTION}

A pandemic can trigger numerous emotions including fear, concern, uncertainty, and anxiety as individuals experience and appraise the effects of this growling COVID-19 virus on the world. It remains speculative regarding the conclusion of this public health crisis. Children are considered a vulnerable group and often mirror the emotions of their parents or guardians thereby magnifying the psychosocial impact of this global health challenge on them, especially if their parents are not coping well during this time. Play is a very important aspect of a child's development; it helps to develop their fine and gross motor skills as well as their language and socialization skills (Kessel, 2018; Anderson-McNamee \& Bailey, 2010). During this time, play may be significantly impacted as some children may be restricted to their homes and may not be able to play outside, they may also not have any other children at home to play with or they may be fearful to play outside. Children may experience the pandemic and the related restrictions as a traumatic experience, where they were unexpectedly taken out of school and taken away from their norm, suddenly not permitted to physically interact with their teachers and friends and compelled into a absolutely different and unique situation; where they are required to participate in distance learning and with little to no interaction with their peers.

\section{HOW CHILDREN AT EACH DEVELOPMENTAL LEVEL ARE COPING}

Infants and toddlers at this time are not cognizant of the intricacies of the pandemic happening around them and the extent to which they may be greatly impacted. Children of this age may experience pleasure from the accessibility of their parents who work from home. Parents should maximize on this opportunity to support their children and participate in their academic and psychological development.

\section{A. Effects of COVID-19 on pre-school age and recommendations}

Pre-school children may not fully appreicate what is happening around them, but they may have feelings of helplessness and uncertainty. These children may regress psychosocially even with skills that they may have already acquired prior to the start of the pandemic. The regression may arise due to the overwhelming concerns they may have without adequate opportunities to express themselves (The National Child Traumatic Stress Network, 2020). They may also miss their friends and the interactions they would have had at school or day care facilities.

It is recommended that these children be reassured, also that parents establish regular family routines, plan comforting activities, play with them, demonstrate patience and tolerance when dealing with these children and avoid or limit their exposure to the media (The National Child Traumatic Stress Network, 2020).

\section{B. Effects of COVID-19 on school-age and recommendations}

School-age children usually feel confident in their abilities to respond to challenges in their lives based on their past experiences, but at this time that confidence may be eroded and they may feel a sense of fear and concern for their own safety and the safety of their family members. This worry or concern may cause the children to experience sleep disturbances including insomnia, hypersomnia or delayed sleep phase disorder, which may create concentration challenges, generally or with their online educational activities. 
It is recommended that parents and guardians exercise patience and tolerance as well as provide reassurance during this time. Additionally, parents should provide an opportunity for play sessions and regular exercise and staying in touch with their friends via telephone and internet. In an effort to reduce children's fears, parents should discuss the current outbreak and encourage questions and including family and community strategies to manage the situation. It is best to limit media exposure and parents should address contemporaneous stigma or discrimination and clarify misinformation that they may have been exposed to (The National Child Traumatic Stress Network, 2020).

\section{Effects of COVID-19 on adolescents and recommendations}

Adolescents may also be greatly impacted by this pandemic, as adolescents usually prefer to spend time with their friends than their families. Home confinement limits the communication preferences of adolescents. They may react to this experience by being easily agitated and demonstrating a low energy and interest in activities, along with sleep and appetite disturbances.

It is recommended that they are also reassured, and parents should also exercise patience and tolerance with them during this time. Encourage them to discuss the outbreak experience with friends and family if they desire. Allow them to stay in touch with their friends via telephone and internet with supervision and monitoring. In addition, limit media exposure, but discuss what they hear and clarify misconceptions (The National Child Traumatic Stress Network, 2020).

\section{Effects of COVID-19 on academics}

Prior to the Outbreak of COVID-19, children in Jamaica were primarily engaged using face to face classroom teachings. The pandemic has caused unprecedented changes in the learning milieu in this country's history, forcing administrators to utilize innovative methodologies to engage students in teaching and learning activities for extended periods. One of the challenges developing countries experience is a limitation in resources. Additionally, in Jamaica it is estimated that $30-40 \%$ of the population of school children, especially those in rural areas and low-income communities, do not own an electronic device nor have continuous reliable access to internet service due to the limited bandwidth from the two major telecommunication companies on the island (Clarke, 2020).

Children are now being engaged in this 'new' format of learning via online media, which is proving to be a challenge. The Ministry of Education in Jamaica has entered into an agreement with the two main telecommunications companies in the country to subsidise access rates for specific educational websites. Whilst this was a good venture to alleviate the strain on some parents; there are still some children who do not own electronic devices and it may be necessary to use parents' phone to gain access to educational sites. The alternative access may pose challenges with synchronous learning especially when there is inconsistent connectivity. These challenges are common among Jamaican children who have had new expectations imposed on them. With no alternative strategies developed to help those who are unable to access the lessons, it is uncertain the impact this will have on their academic continuity. In addition, significant responsibility has been placed on parents, some of whom are not equipped educationally or emotionally to support their children in this process.

It is recommended that the Ministry of Education mandate schools not to offer any new concept or topic during this time, to ensure that children who are unable to access the online lessons are not disadvantaged. Nevertheless, at this time classes can be centred on revision to improve the students' understanding. In addition, if schools decide to test students during this time, the results should not be included in their permanent record but as benchmark for the teachers to acquaint themselves with children's academic capacity as well as to guide continued educational engagement. The schools can also provide additional support to parents to ensure that the goal of the institution is being met during this time.

Children need all the support they can get during this time to ensure that they are not overwhelmed with these unprecedented changes in their lives and lessen the impact that this traumatic experience may have on their lives.

\section{REFERENCES}

[1]. Anderson-McNamee, J., \& Bailey, S. (2010). The Importance of Play in Early Childhood Development. Retrieved from, http://health.msuextension.org/documents/MT201 003H.pdf

[2]. Clarke, P. (2020, April 23). Students juggle phones in online home classes. The Gleaner Jamaica, p. A3.

[3]. Kessel, J. (2018). "Let Our Children Play: The Importance of Play in Early Childhood Education". University of Montana Journal of Early Childhood Scholarship and Innovative Practice 2 (1) article 5: 1-6.

[4]. The National Child Traumatic Stress Network. (2020). Parent/Caregiver Guide to Helping Families Cope With the Coronavirus Disease 2019 (COVID-19). Retrieved

from, https://www.nctsn.org/resources/parent-caregiverguide-to-helping-familiescope-with thecoronavirus-disease-2019 